\title{
Editorial
}

\section{On the Imitation of Nature}

More than a palliative or emergency measure, restoration provides a model for an ecologically sound relationship with nature.

From time to time I and various contributors to R\&MN have complained that environmentalists have not taken restoration seriously enough. Very little has been said, however, about why they should take it seriously, or about just what role restoration might be expected to play in an environmental program.

Of course at least part of the answer is obvious. As a healing technology, a form of ecological medicine, restoration offers the hope not merely of halting or slowing environmental damage, but of reversing it. It is in this sense the other side of the environmental coin - the program of prognosis and healing that complements, balances, and completes the preservationist program of diagnosis and protection.

But I would like to suggest something beyond this. Recently, reading the history of the environmental movement, I have been struck by the deep division between preservationists and utilitarians that has characterized the movement almost from the beginning.

At first, according to Historian Stephen Fox's John Muir and His Legacy: The American Environmental Movement, environmentalists worked together to secure the designation of Yosemite National Park in 1890. But by 1908 , when the issue of damming Yosemite's Hetch Hetchy River arose, there was deep division within the movement, and deep-seated and sometimes bitter disagreement between preservationists like Muir, who stressed esthetic and ethical values in their appeal for preservation of wilderness, and utilitarians like U.S. Forest Service Head Gifford Pinchot, who were more sympathetic to the use and management of natural resources.

This division has turned out to be fundamental, and indeed much of the history of the environmental movement since those early years has been shaped by the field of tension generated by these two poles of opinion. At times one view has had the upper hand, at other times the other has prevailed. In general, the first two phases of the movement, during roughly the first and fourth decades of the century, were strongly utilitarian in tone. The more recent phase, which took shape during the 1960 s, has been more decidedly preservationist.

All this makes fascinating reading. My feeling, however, is that too much of this division and polarization is unfortunate. For one thing, it divides environmentalists, possibly reducing their political effectiveness. For another, it encourages either/or thinking, imposing choices between two positions, neither of which is satisfactory all by itself. Both preservation and policies for proper use are obviously necessary ingredients of a sound environmental program, but neither idea by itself is complete. Neither offers the one thing we must demand from any environmentalism worthy of the name: an ecologically sound relationship between human beings and the rest of nature.

Quite simply, the utilitarian agenda retains too much of the old human arrogance and species chauvinism that has been at the root of so much wanton despoliation of nature. The preservationist agenda, on the other hand, with its preoccupation with wilderness as an ideal, often goes too far in the other direction. Tending to exclude people and to separate them from nature, it hardly provides a basis for anything so complex as a satisfactory relationship with the environment.

This is where I see the greatest significance for the idea of ecological restoration. As a form of agriculture that borrows its objectives directly from nature, it seems to me that restoration combines the preservationist and utilitarian traditions into an idea that is bigger, more comprehensive, and sounder than either of these traditions by itself. Restoration is utilitarian in means but preservationist in intention. It borrows its techniques from agriculture, but its inspiration and objectives directly from the ideal of wilderness preservation. It implies manipulation, but always with respect.

This is why I see restoration not merely as an emergency or palliative measure, but as an ideal for a sound relationship between human beings and their environment. Since restoration depends on wilderness both as a model and a source of material, the idea of restoration includes wilderness preservation. But, unlike preservation alone, restoration also comprehends a wide range of vital human activities. In the strictest sense - the actual species-by-species recreation of plant and animal communities - restoration may be a fairly esoteric kind of activity. But this activity represents an idea - the idea of the imitation of nature - which has far broader implications for human life.

Thus, restoration, in the narrowest sense, may give us forests and prairies, perhaps to replace those lost to development. But this represents the imitation of nature only in its purest, most concrete form. More broadly construed to include the imitation of nature in more abstract ways, restoration offers lessons for agriculture, medicine, and even architecture.

In this sense, for example, the many forms of organic agriculture are examples of restoration. So is sustained yield forestry. And preventive medicine. And organic architecture. And environmentally sensitive approaches to landscape architecture and even urban design. 
Clearly, this is the kind of breadth we need in an environmental philosophy. To test the idea, consider for a moment what an environmental program based on and unified by this idea might look like. Where the utilitarian tradition offers only rigorously managed landscapes like those that horrified Aldo Leopold on his trip to Europe in 1935, an environmentalism based on restoration offers a landscape in which human use is in some kind of dynamic equilibrium with wilderness and nature generally.

Similarly, where preservation offers only dwindling wilderness preserves, increasingly remote from daily life, the restorationist agenda offers a wilderness continuum linking the rain forests of the Amazon basin and the Gates of the Arctic National Park with the quarter acre of restored vegetation in a neighborhood park in the Bronx.

Above all, it keeps human beings in the picture, in intimate contact with nature, changing the landscape unapologetically as all creatures do, but with humility and an abiding respect for ourselves as well as for the rest of nature.

\section{Special Notice}

Intensive editorial planning for Restoration \& Management Notes will be under way throughout 1985 . Issues to be considered include the editorial focus of the journal, content, style (including use of metric units), the establishment of an editorial board, and whether to include refereed papers. During this period we are especially eager to hear our readers' views on these matters. We would also welcome queries regarding contributions that might be considered for publication as refereed papers. Please direct comments and suggestions to the editor.

William R. Jordan III 